\title{
Resonancia magnética en la evaluación de los anillos vasculares
}

\author{
Pilar Amaiz G. '; Gonzalo Urcelay M.'; Felipe Heusser R. '; \\ Claudio Arretz V. '; Guillermo Ríos $\mathrm{O}^{2}$
}

\section{Nuclear magnetic resonance in the diagnostic evaluation of vascular rings in children}

A. newborn girl with a pedomingntly ight double astir arc, a socular posterior dilatetion of the left aorfe are structures and secondary rachea compression wos evaliated by nuc'eor magnetic resenance and her anatomicat abnorma ities were afterwards substarciated al surgery. Successful le'i artic arc resection between the lefica'otid and subelavian arteries together with ductus orteriosus section were carried out, thus contirming the usefulness of this non invasive diagnostic method in the precise onctomical descriphon and diognosis of vascula rings

(Key words: dousle arric arc, recheal compress on, strdor, vascu a rings, nuclear magnetic rescnance.)

Se denomina anillo vascular a ciertas anomalías del desarrollo morfológico del arco aórtico y las estructuras vasculares asociadas que causan compresión de la tráquea y el esófago. Estos defectos resultan de una falla de la fusión c involución de los arcos vasculares embrionarios durante la formación de la aorta torácica, las arterias pulmonares y el ductus arterioso. Los más frecuentes son' doble arco abrtico completo; doble arco aórtico con un segmento atrésico (frecuentemente el arco es derecho y el scgmen. to atrésico está en la porción posterior del izquierdo); arco aórtico derecho con arteria subclavia izquierda aberrante (e) ligamento arterioso completa el anillo). El arco aórtico izquierdo con arteria subclavia derccha aberrante no causa anillo vascular.

La resonancia nuclear magnćtica es un método sobresaliente de obtención de imágenes que provee excelente contraste de los tejidos blandos. Su empleo clínico para obtener imágenes cardiovasculares es cada vez más frecuente en adultos y niños, prestando el máximo de utilidad en la excelente definición de los vasos torí-

1. Departamentos de Pediatría y Enfermedades Cardiovasculares, Escuela de Medicina, Pontificia Lniversidad Católica de Chile.

2. Departamento de lmágcnes. Sección Resonancia Magnética. Clínica Alemana de Santiago. cicos extracardíacos que proporciona, como se ilustra en el caso de la paciente que se describe a continuación.

\section{Caso clínico}

Niơa recién nacida de térunino con estridor inspiratorio purmanente desde el nacimiento. regurgitacion de contenido gástrico. difícultad para manejar las secreciones bronquiales, retracción subcostal, cianosis con el llanto en coincidencia con desaturación de la sangre atterial (saturación $80 \%$ por oxjmetrías de pulso). En las radiografías de tórax se observaba el arco abrico al lado derecho. El esofagograma registraba imúgenes de compresión bilateral y pusterior del esofago, que tomaba forma de reloj de arena (figura 1), con importante reflujo gastroesofágico del medio de contraste. En la ultrasonografía cardíaca (bidimensional y Doppler) el aspecto del corazon era normal, el cayado aórtico estaba al lado ócecho y se obtenian imagenes sugerentes de arteria subclavia izquierda aberrante. Mediante resonancia nuclear magnélica (fitgura 2) se obtuvieron imágenes de dable arco abrtico, donde predominaba el derecho, que comprimía la tráquea, y una dilatación sacular en el extremo posterior del arco izquierdo. A la edad de quince días se realizó toracotomía lateral izquierda. en la que se comprobó la anomalía anatómica descrita, se secciond y Itgó cl ductus arterioso persistente y la porcion antecior del arco aórtico izquierdo. entre las arterias caró. tida $y$ subclavia izquierdas, de modo que esıa última quetó unida a la aorta descendente derecha como una arteria subclavia izquietda aberrance (figura 3). La evolución postoperaloria ha sido satisfactoria. después de un mes de seguimiento el estridor sólo aparece en el llanto. la niâa está sin síntomas de reflujo y aumenta bien de peso. 

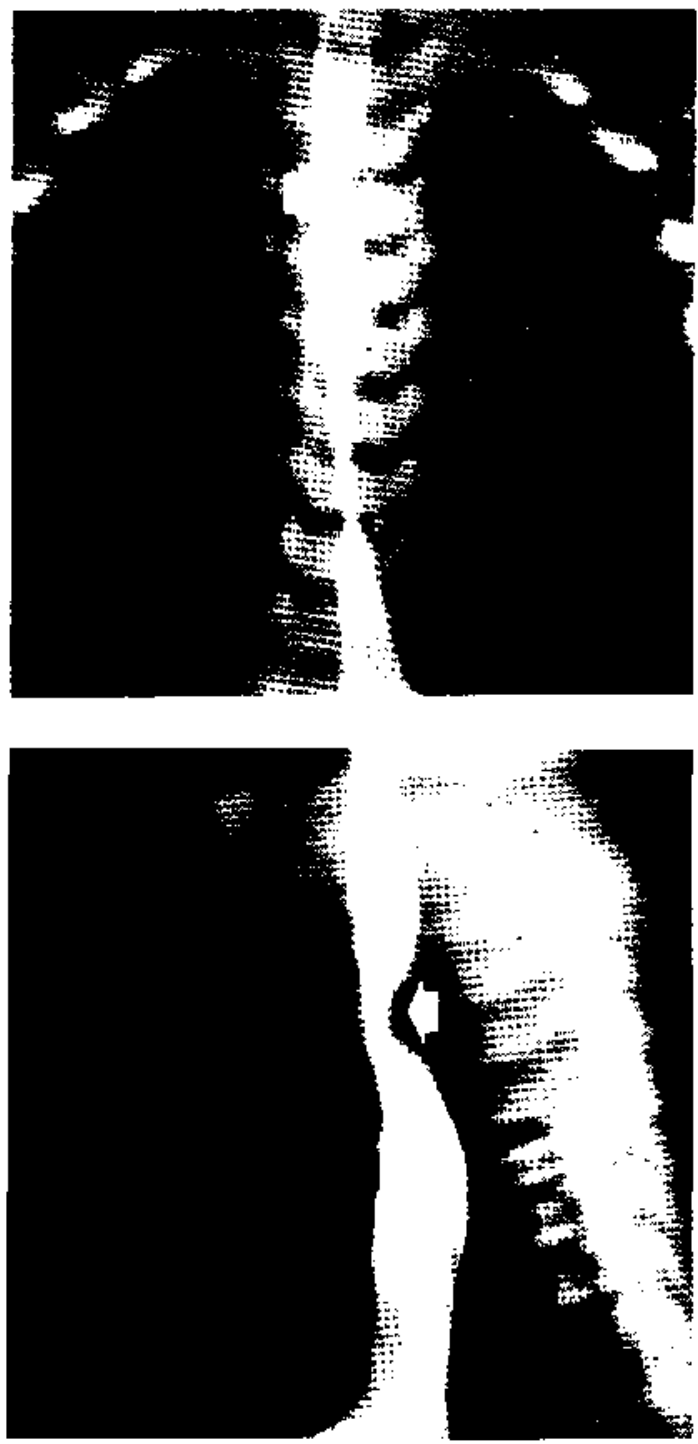

Fitsura I: Arriba: delormidad cin [eloj de arema del esbfit-

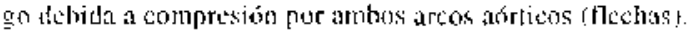

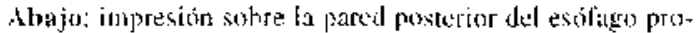
dacida por dilatación sacular de lat porción postenol del areo aóttico izquierdo.

\section{Comentario}

Como en la paciente que se ha prescntado. cuando se sospecha anillo vascular se debe bacer radiografías de tortax con contraste de esílago. Puesto que en la mayoría de los casos el arco aórtico está a la derecha. es posible registrar en cllas una impresion sobre e] borde dere- cho del esofagograma en las placas frontales. La porción izquierda de un doble arco aórtico también puede causar impresiones sobre el borde de ese lado. En las placas laterales se observa una intpresión sobre la pared esofágica posterior y desplazamiento anterior de la tráquea, sceundariamente a la existencia de un vaso anómalo retruesofágico ${ }^{2}$.

La ultrasonogralía petmitc evaluar la anatomía cardíaca propiamente tal, que suele ser normal en estos casos, pero juega un rol limitado en el esludio de las estructuras vaseulares extracardacas y el sitio de compresión del csófago y la tráquca. Una vez formulado el diagnóstico, es necesario precisar lit anatomía del anillo vascular, sus relaciones con las estructuras adyacentes, prever la prescncia de coartación aórtica y elcgir sin equivocaciones el silio de la toracotomia, para lo cual las opciones son la angiogralía, la tomografía axial computadorizadil o las imagenes de resonancia magnética. La angiografía permite delinear bien la anatomía vascular, pero no la refación de los vasos con las estructuras vecinas $y$, además, es invasiva. La comografía axial sólo mucstra imágenes on cl plano axial y estas son de baja resolución cuando se trata de estructuras vasculares. Estos dos mélodos exponen a radiuciones ionizantes $y$ cmplcan medios de contraste yodaklos.

La resonancia magnética es. por su parte, muy útil para cvaluar la aorta torácica en adultos y ninos ${ }^{3-7}$, no cs invasiva o emplca radiaciones o requiere de medios yodados de contraste, sin embargo ofrece muy buena información anatómica en varios planos y nitido contraste natural chire las tejidos. Todo lo anterior permite delinir con exactitud la anatomía vascular y sus relaciones con la vía aćrca mediante este proecdimientox ${ }^{x}$ como sc confirmó en el caso que se comenta, comprobando que es la mejor opción para el estudio preoperatorio de pacientes con anillos vasculares.

\section{Resumen}

Se describe $e 1$ caso de una niña recién nacida con doble arco ártico de predominio derecho. dilatación sacular de la porción posterior de las estructuras del arco izquicrdo y compresión secundaria de la tríquea, que lue evaluada por re- 

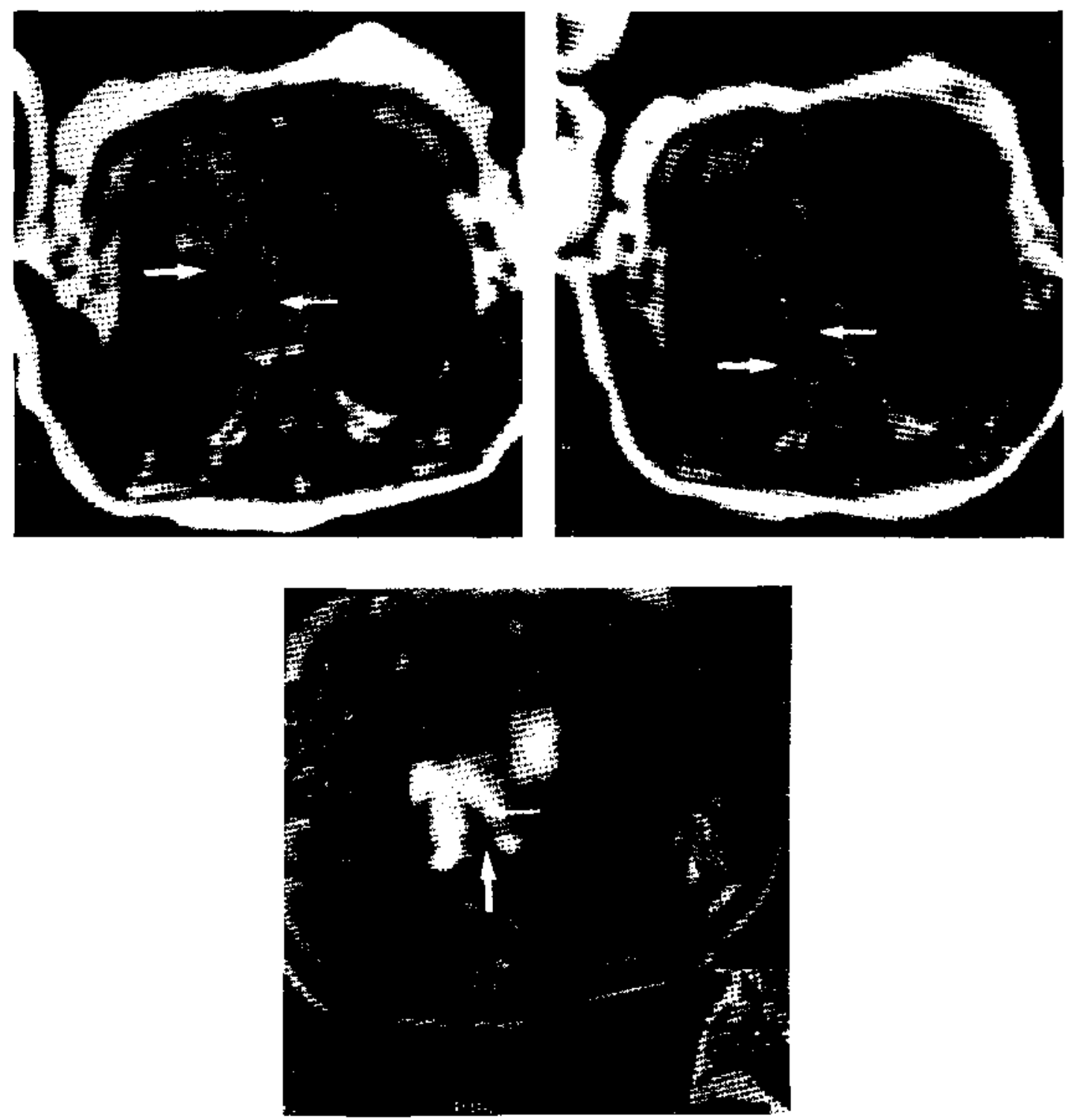

Figura 2: Imnigucnes por resonncia nuclear magnética. Secuencıa TI. Corles axiales. Izquierda: arco aórtico derecho predominate ( lecha grande? y arco izquierdo pequero (flecha chica). Entre ambos ta tráquea y el esófago. Derecha: dilatación sacular posterior del arco á́rtico izquierdo (fiecha grande) que deforma la pared posteror del esófago (flecha chica). Abajo: Secuencia angjográfica. Las estrucliras vasculares se registran en blanco. Ambos arcos abrticos comprinuen la trúquea (tlechá chica) y deforman el esófago (flecha grande).

sonancia nuclear magnética, confirmándose las lesiones anatómicas descritas con esta téenica durante la intervención quirúrgica, en la que se resecó el arco aórtico izquierdo entrc las arterias carótida y subclavia, seccionando y ligando cl ductus arterioso. De este modo se confirma e ilustra la utilidad de las imágenes de resonancia magnética en la evaluación y definición de la anatomía de los anilllos vasculares.

(Palabras clave: doble arco aórtico, compresión traqueal, cstridor, anillos vasculares, resonancia nuclear magnélica.) 

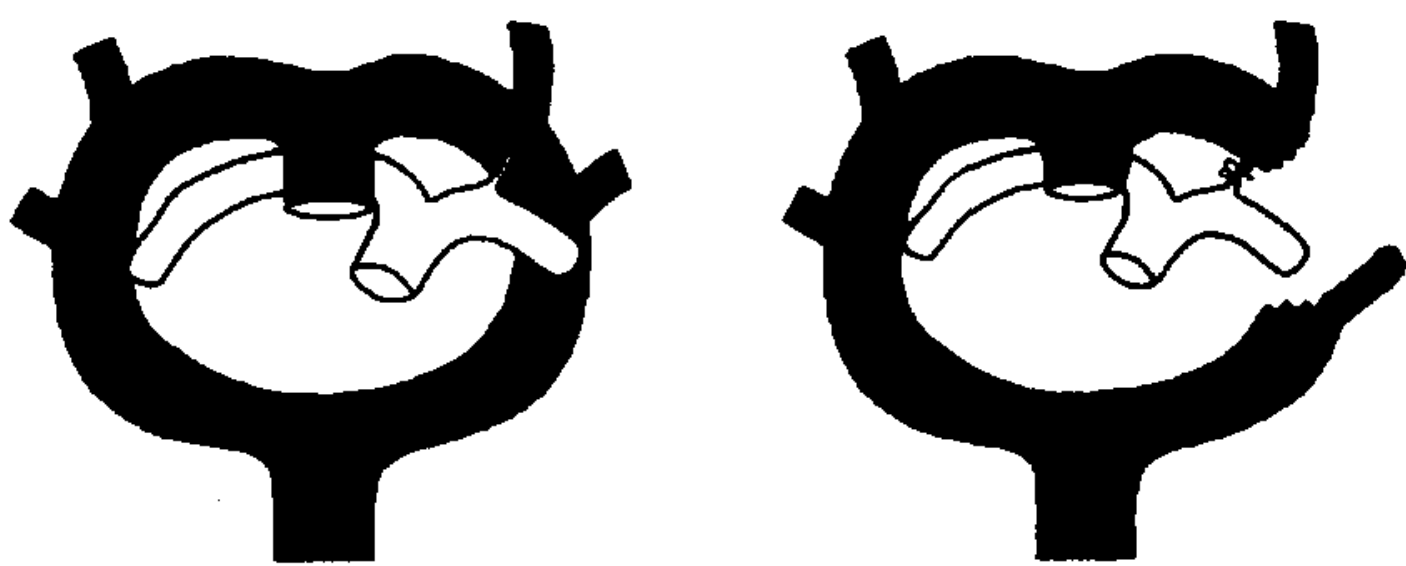

Figura 3: Esquema del doble arco aórtico de la paciente (izquierda) y del procedimiento quirúrgico realizado (derecha).

\section{Referencias}

1. Higgins $C B$ : Thoracic aortic disease. En: Higgins $C B$ (ed), Essentials of cardiac Radiology aud Imaging. Lippincot Company, 1992: 179-214.

2. Tonkin IL, Elliot LP, Bargeson LM Jr: Concomitant axial cineangiography and bariurn esophagography in the evaluation of vascular rings. American Journal of Radiology 1980; 135: 69-75.

3. Amparo EG. Higgins CB. Hoddicck $W$ et al: Magnetic resonance imaging of aortic disease. Preliminary results. American Journal of Radiology, 1984; 143: 1203-1209,

4. Burrows $P E$. MacDonald $C E$ : Magnetic resonance imaging of the pediatric thoracic aorta. Seminars in Ultrasound, CT and MRI, 1993; 14: 129-144.

5. Bisset GS 3d, Sirffe JL, Kirks DR. Bailey WW: Vascular rings: MR imaging. Arnerican Journal of Radiology 1987: 149:251-256

6. Phillips RR. Culhum JA: Pulmonary artery slings and hypoplastic right lung: diagnostic appearences using MRI. Pediatr Radiol 1993; 23: 117-119.

7. Bisset GS: 3d, Magnetic resonance imaging of congenital heart disease in the pediatric patient. Radiol Clin North Am 1991: 29: 279-291

8. Dithfield MR, Culham JA: Assessment of airways compression by MR imaging in children with aneurysmal pulmonary arteries. Pediatr Radiol 1995; 25: 190-19].

\section{AVISO A LOS AUTORES}

Con el objeto de dar prioridad a los trabajos de investigación, en vista de las limitaciones de espacio de la Revista Chilena de Pediatría, el Comité Editorial ha acordado restringir la impresión de casos clínicos a un máximo de dos por cada número. 